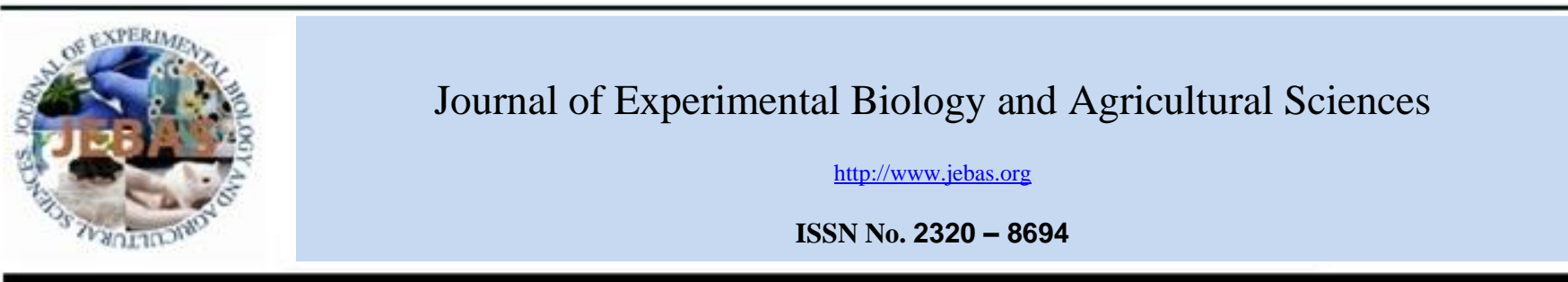

\title{
CURRENT UNDERSTANDING OF THE MECHANISMS OF HEAT STRESS TOLERANCE IN RICE (Oryza sativa L.)
}

\author{
Kananbala Sarangthem, Seemasundari Yumlembam, Sheikh Benazir, \\ Rozina Yendrembam, Khaling Mikawlrawng*
}

Manipur University, Canchipur, Department of Botany, Plant Physiology Laboratory, Imphal, Pin code: 795004

Received - January 28, 2021; Revision - July 21, 2021; Accepted - July 26, 2021

Available Online - October 20, 2021

DOI: http://dx.doi.org/10.18006/2021.9(Spl-3-NRMCSSA_2021).S321.S329

\section{KEYWORDS}

Rice

Heat stress

Tolerance

Mechanism

\begin{abstract}
Various studies reported by scientific communities such as NASA's Goddard Institute for Space Studies (GISS) indicated an increase in average global temperature by approx. $0.8{ }^{\circ} \mathrm{C}$ since 1880 . Rice (Oryza sativa L.), a heat sensitive plant cereal crop could be greatly affected by heat stress due to global temperature rise. Thus, it is envisaged that rice productivity could markedly decrease due to a rise in mean atmospheric temperature. Different studies have been reported possible mechanisms of heat stress tolerance in Rice. The present review will therefore discuss the current fundamental understanding of heat tolerant mechanisms involving heat shock proteins, plant hormones, plant growth regulators, osmoprotectants, and the importance of membrane thermal stability in rice.
\end{abstract}

* Corresponding author

E-mail: khaling55@gmail.com (Khaling Mikawlrawng)

Peer review under responsibility of Journal of Experimental Biology and Agricultural Sciences.

Production and Hosting by Horizon Publisher India [HPI] (http://www.horizonpublisherindia.in/).

All rights reserved.
All the articles published by Journal of Experimental Biology and Agricultural Sciences are licensed under a Creative Commons Attribution-NonCommercial 4.0 International License Based on a work at www.jebas.org.

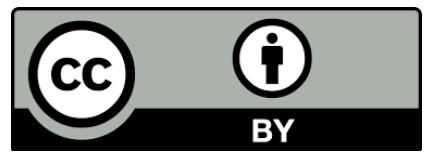




\section{Introduction}

Heat tolerance can be defined as the ability to undergo normal plant growth and to produce normal yields when exposed to heat stress (Yamanouchi et al., 2002; Wahid et al., 2007). Understanding the physiological mechanisms underlying heat stress response and tolerance in plants is of utmost importance in the present context of an increase in global temperature (Fahad et al., 2017; Prasad et al., 2017; Govindaraj et al., 2018). Figure 1 suggested that heat stress causes adverse effects on the growth and development of plants, ultimately affecting the yield of the crop plant (Hasanuzzaman et al., 2012; Hasanuzzaman et al., 2013). High temperature stress during reproductive or grain-filling stages is shown to have negative effects on grain quality and yield (Bahuguna et al., 2015). The photosynthetic process was found to be negatively affected when rice plants were exposed to a temperature of $3.6^{\circ} \mathrm{C}-7.0^{\circ} \mathrm{C}$ higher than critical temperature (Oh-e et al., 2007; Fahad et al., 2016a). Based on the prevailing world food crisis and present understandings of the unwanted impacts of the rise in global temperature on cereal crops, there is an urgent need to understand the various approaches and mechanisms to address heat stress and to develop new heat-tolerant rice cultivars to cope with these problems. Various studies have implicated the importance of scavenging reactive oxygen species, maintaining the normal structure and functionality of enzymes and proteins for efficient heat stress tolerance (Maestri et al., 2002; Lei et al., 2018). Thus, with the ever-increasing need to meet the global food crisis it becomes imperative to properly decipher various mechanisms to address temperature stress in rice plants.
Heat stress leads to degradation of Rubisco, thereby affecting plant photosynthetic process and yield. It also causes spikelet sterility and leads to reduce in reproduction in rice. Apart from many other damages, it causes reduce in auxin level which is required for maintaining spikelet fertility, reduces membrane stability, and causes electrolytic leakage, thereby causing a decline in seed set and yield.

\section{Avoidance mechanisms}

High temperature mostly affects rice plants during the anthesis, i.e. at the time of opening of flowers, thereby decreasing the fertility of the spikelet. Exposure to high temperatures for one hour has been reported to induce spikelet sterility. However, various studies have also indicated that after one hour of flowering, the spikelets are less affected by exposure to high temperatures (Satake \& Yoshida, 1978; Jagadish et al., 2007; Julia \& Dingkuhn, 2012). Thus, spikelet sterility could be an important trait to study rice genotypes for their ability to tolerate heat stress (Weerakoon et al., 2008). Early morning flowering when the air temperature is cooler is a useful trait that reduces spikelet sterility (Yoshida, 1981). Thus, understanding genes that control anthesis and flowering time is of utmost importance to decipher the mechanism of heat stress tolerance. Similarly, genes responsible for early flowering can be studied to explore various possible mechanisms for imparting heat tolerance in rice (Sheehy et al., 2005; Bheemanahalli et al., 2017). Studies have indicated a close relationship between spikelet fertility and panicle temperature (Julia \& Dingkuhn, 2013), and suggested that one avoidance mechanism for heat stress is by

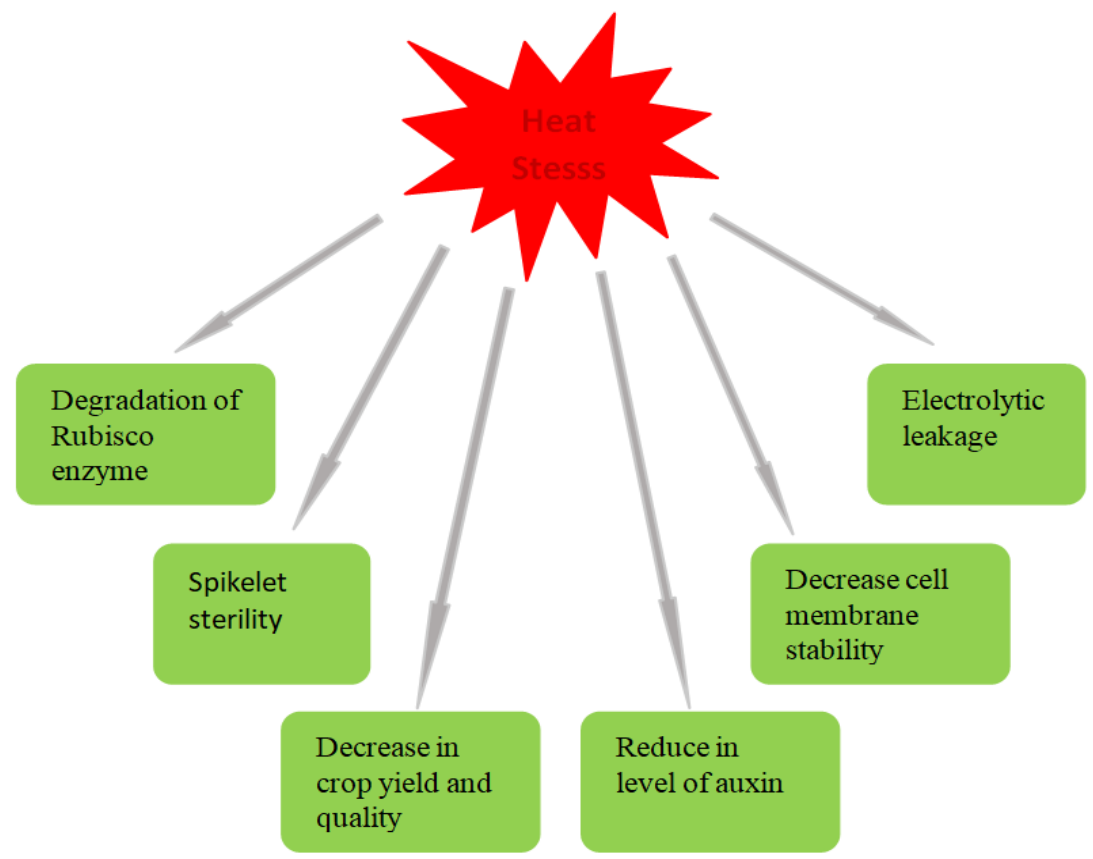

Figure 1 Some of the detrimental effects of heat stress in rice plant.

Journal of Experimental Biology and Agricultural Sciences

http://www.jebas.org 
lowering panicle temperature by transpirational cooling (Xiong et al., 2014), and rice plants can decrease the panicle temperature up to $10{ }^{\circ} \mathrm{C}$ by transpiration, and thereby helps in maintaining spikelet fertility. Thus, rice plants that have longer and erect top leaves help in protecting the panicle from direct sunshine, and thereby confer heat tolerance.

\section{Tolerance mechanisms}

The ability to tolerate heat in rice is different for different species and cultivars, even different organs and tissues of a plant may exhibit varying abilities to tolerate heat stress. Various studies have reported the role of heat shock proteins, plant hormones, osmoprotectants, and membrane thermal stability in this regard.

\subsection{Role of heat shock proteins (HSPs)}

The synthesis and accumulation of HSPs is a prompt response after exposure to high temperatures and it is considered as one of the most important adaptive strategies to overcome the deleterious effects of heat stress. The fast build-up of HSPs in soft tissue plays important role in conferring thermostability at the cellular level; thereby promote plants to perform better under heat stress conditions (Wahid et al., 2007; Keller \& Simm, 2018). Heat shock factors (Hsfs), which are the transcriptional activators of HSPs, and HSPs have been reported for their roles in various types of abiotic stresses including heat stress. HSPs prevent the accumulation of proteins with anomalous conformations and eliminate non-native aggregations formed during stress with ubiquitin-mediated degradation of these proteins (Kotak et al., 2007). It is predicted that heat tolerance and heat shock proteins (HSPs) production are closely related (Huang \& Xu, 2008).

Transgenic rice inserted with HSP101 from Arabidopsis thaliana cDNA indicated the important role of HSP in enhancing heat stress tolerance. The transformed transgenic rice showed the ability to undergo normal growth and development as compared to their untransformed counterpart (Katiyar-Agarwal et al., 2003). The expressions of HSPs in anther were also found to be elevated in heat stress-tolerant rice variety. Such variety showed higher spikelet fertility (Jagadish et al., 2010). Thus, the ability to express more HSPs is an important heat stress tolerance mechanism in rice (Chang et al., 2007), and a deeper understanding of the elevated production of HSPs is of great significance for alleviating heat stress.

\subsection{Role of plant hormones and plant growth regulators}

Different plant hormones and plant growth regulators are reported for their protective roles against heat stress in rice plants. Studies on exogenous application of plant hormones and plant growth regulators (PGR) on rice indicated important roles of ascorbic acid, alpha-tocopherol, salicylic acid (SA), glycine betaine (GB), auxins, brassinosteroids (BRs), and methyl jasmonates (MeJA) in ameliorating the adverse effects of high temperature stress (Mohammed \& Tarpley, 2011; Fahad et al., 2016b). Thus, understanding how these plant hormones function will be of great help in the overall search for mechanisms of high temperature tolerance in rice plants.

Salicylic acid has been reported for its role in the regulation of various physiological processes in plants in response to abiotic stresses (Hayat et al., 2010). Under heat stress, exogenous application of salicylic acid ( 1 and $10 \mathrm{mmol} \mathrm{L}^{-1}$ ) could lead to higher grain yield, spikelet number per panicle, and setting rate (Zhang et al., 2017). This study even suggested the roles of IAA, sugars, and antioxidant enzymes along with SA in avoiding spikelet degeneration. Salicylic acid treatments in rice also lead to induction of Class II HSP (Oshsp18.0) (Chang et al., 2007). Another study showed that the application of SA resulted in increased antioxidant capacity, thereby avoiding membrane damages in rice plants (Mohammed \& Tarpley, 2011).

Various studies have reported the ability of methyl jasmonates (MeJA) in advancing the flowering time in the morning, which is an important mechanism to mitigate heat stress. Studies on the effects of MeJA on rice floret opening indicated that it significantly induces the opening of rice florets within about 30 min, with the most rapid induction occurring just $6 \mathrm{~min}$ after treatment. The numbers of induced opening florets are correlated with MeJA concentrations. Higher concentrations of MeJA induced more florets (Zeng et al., 1999). Another study showed that the application of MeJA resulted in the opening of flowers within 80 mins. It also resulted in advancing the time of flower opening by two hours and also led to an increase in the opening of more flowers, which were supposed to be opened the next day (Kobayasi \& Atsuta, 2010).

Studies on the relationship between heat stress tolerance and Brassinosteroids (BRs) signaling showed that disruption of the gene brassinosteroid insensitive 2 (BIN2) that encodes for a negative regulator of the BRs receptor Brassinosteroid Insensitive 1(BRI1) leads to increase tolerance to a variety of abiotic stress including heat shock (Koh et al., 2007). Brassinosteroid's application resulted in a higher accumulation of major heat shock proteins and several translation initiations and elongation factors and could maintain the net photosynthetic rate, enhanced stomatal conductance, stomatal limitation, and water-use efficiency (Dhaubhadel et al., 2002; Sonjaroon et al., 2017). Brassinosteroids application also has been reported to stimulate stress tolerance by positively regulating the synthesis of endogenous hormones, such as indole-3-acetic acid, zeatin riboside, jasmonic acid, brassinosteroids, and gibberellic acid (Anwar et al., 2018). Foliar application of 24-epibrassinolide $(0.5,1$, and $1.5 \mathrm{ppm})$ on rice cultivars (Pusa Sugandh 5 and Nerica L 44) showed a strong 
positive relationship between grain yield and leaf photosynthesis. The foliar application of brassinosteroid, salicylic acid, and calcium (calcium chloride) has been suggested to ameliorate the decrease in PSII efficiency at pre-anthesis in rice (Chandrakala et al., 2013).

The reproductive stage in rice requires an optimum level of hormones like auxin and other energy-producing compounds. Naphthalene acetic acid (NAA) applied immediately after flowering improved the crop tolerance to heat stress which leads to better crop productivity. The decrease in rice crop yield and quality due to heat stress can be controlled with optimum level $\left(20 \mu \mathrm{mol}^{-}\right.$ L) of exogenous application of Naphathaline acitic acid (NAA) (Naeem et al., 2019). Auxin also plays an important role in maintaining spikelet fertility. The reduced level of active IAA could cause pollen abortion and male sterility. High temperature could also lead to a reduction in the level of auxin (Sonjaroon et al., 2017). Spraying of naphthaleneacetic acid could stop the reduction of pollen tube growth and could reverse the spikelet sterility in rice (Zhang et al., 2018).

A study using L-galactono-1,4-lactone dehydrogenase overexpressed (GO-2) and L-galactono-1,4-lactone dehydrogenase suppressed (GI-2) transgenic rice as experimental materials showed that application of ascorbic acid resulted in significantly lowered maximal quantum yield of photosystem II (ФPSII) in GI2 , and higher in GO-2 compared to wild type rice, whereas the content of reactive oxygen species (ROS) was the highest in GI-2, thereby suggesting that higher ascorbic acid content reduced the accumulation of ROS and maintained the function of rice leaves. Thus, it is believed that high ascorbic acid content could improve the rice resistance to high-temperature stress (Zhang et al., 2018).

\section{Role of osmoprotectants}

Heat stress in plants leads to adaptive accumulation of various types of osmoprotectants such as glycine betaine, trehalose, and proline, which are not deficient in heat stress-sensitive plants. Thus, it is suggested that exogenous application or inherent ability to accumulate these osmolytes could help plants in tolerating heat stress (Jain et al., 2001; Rasheed et al., 2011; Sakamoto \& Murata, 2002). These solutes play important role in the osmotic adjustment and maintain the water contents and protect leaf cells under abiotic stresses, especially under drought and heat stress. Lower production of osmoprotectants under heat and drought stress could expedite the assaults by ROS, thereby leading to senescence of leaves.

Glycine betaine (GB) is an important osmolyte that helps in imparting heat stress tolerance in plants (Sakamoto \& Murata, 2002). It has been reported for its role in protecting heat degradation of Rubisco, citrate synthase, and other enzymes
(Mäkelä et al., 2000). Under high temperature stress, many plants could accumulate glycine betaine, but rice and many other plants cannot do so. Thus, exogenous application of glycine betaine could increase yields under high temperatures, possibly by enhancing antioxidant levels, which might have protected the enzymes and membranes from degradation (Quan et al., 2004; Mohammed \& Tarpley, 2011; Annunziata et al., 2019). The application of glycine betaine could also help in preventing the Rubisco enzyme from being degraded (Dionisio-Sese et al., 2000). Glycine betaine has also been reported for its ability to enhance the rate of pollen germination and increase spikelet fertility.

Accumulation of proline under heat stress has been reported to help plants in osmotic adjustment (Szabados \& Savoure, 2010). A study reported that plants with higher content of proline were observed to be less affected by both heat and drought stress as compared to those plants with lower proline content (de Ronde et al., 2004). However, the effect of proline is not independent but relies on many factors, one among them being phytohormones. Brief exposure of rice plants to high temperatures resulted in the rise in proline levels, which is indicative of heat stress (Tang et al., 2008). Rice genotypes that could adapt more efficiently were reported to have more proline content (Ahmed \& Hasan, 2011). Application of proline lowered the Malondialdehyde (MDA) content in rice, which may be due to its ability to increase the antioxidant defense system (Nounjan et al., 2012).

Spermidine (Spd), a widely distributed polyamine has been reported for its adaptive role in heat stress in plants (Das et al., 2014). Most studies have implicated that its antioxidant capacity and ability to reduce the rate of superoxide anion and malondialdehyde (MDA) could have attributed towards its ability to maintain membrane stability under environmental stress (Farooq et al., 2009; Tian et al., 2009). Exogenous application of Spd was shown to cause reduction of propionaldehyde, hydrogen peroxide, and proline contents in rice seedlings, but lead to an increase in glutathione, ascorbic acid, fresh weight (FW), and chlorophyll contents (Mostofa et al., 2014). A comprehensive study showed that Spd could help protect PS II by its ability to increase the light energy used in the photochemical reaction, $\mathrm{Fv} / \mathrm{Fm}(\mathrm{Fv}=$ variable fluorescence; $\mathrm{Fm}=$ maximum $)$, ФPSII (quantum yield of PSII photochemistry = ФPSII), and ETR (relative rate of electron transport $=\mathrm{ETR}$ ). These findings indicated that Spd could have brought about optimization of energy distribution and prevented damages to the structure of the photosynthetic system, and help in the proper functioning of the photosynthetic system. Another study showed that Spd might help in reducing leaf temperature by increasing the rate of transpiration rate and by preventing membrane damage. Spd spraying on two rice species (japonica rice varieties Wuyunjing 24 and Ningjing 3) could significantly promote the rate of seed-setting and grain weight. Exogenous application of Spd also could effectively prevent 
damages caused by heat stress on the photosynthetic systems, antioxidants, and osmotic balance, and could enhance the cellular defense capability. Moreover, it was shown to help in maintaining a temperature suitable for seed-setting rate and grain weight by improving transpiration rate and stomatal conductance, thereby lowering the leaf temperature during heat stress (Tang et al., 2018).

\section{Role of membrane thermal stability}

Membrane thermostability is an important reliable trait that can be used to screen out the tolerant rice genotypes (Sailaja et al., 2015). The cell membrane is one of the main cellular targets to different stresses and maintenance of membrane stability during stress is important for normal physiological metabolism to continue (Levitt, 1980). Cell membrane stability or the reciprocal of cell membrane injury is an important indicator of the ability of a plant to tolerate drought and temperature stress (Sullivan, 1972; Blum \& Ebercon, 1981; Forkar et al., 1988; Sadalla et al., 1990; Reynolds et al., 1994). Thus, the extent of its damage is commonly used as a measure of tolerance to heat and drought.

Electrolytic leakage expressed as relative injury measured at an early grain-fill (EGF) stage was greater in plants grown under high nighttime temperature (HNT) $\left(32^{\circ} \mathrm{C}\right)$ compared with the plants grown under ambient nighttime temperature (ANT) $\left(27^{\circ} \mathrm{C}\right)$. On average, plants grown under HNT showed a $60 \%$ increase in electrolytic leakage compared with plants grown under ANT. Application of vitamin E, glycine betaine, and salicylic acid decreased electrolytic leakage by 31,42 , and $30 \%$, respectively, compared with untreated plants grown under ANT. Membrane thermal stability, when measured as the conductivity of electrolytes leaking from leaf disks at high temperatures, has been suggested as one of the best techniques to evaluate the performance of a plant under high temperatures. Therefore, decreased membrane stability in plants grown under HNT indicated that high temperatures lead to leaky membranes. Application of GB or SA could lead to increased antioxidant capacity that can reduce oxidative damage, thereby increasing membrane thermal stability and reducing leaf dark respiration rates (Abdul-Razack \& Lee, 2009). Thus, GB and SA can be used as exogenous effectors to ameliorate the effects of HNT. Both compounds increased the total antioxidant capacity of the rice plant, thereby presumably decreasing the leaf dark respiration rates and electrolytic leakage, hence increasing the yield. Genetic variability for membrane thermostability revealed that membrane thermostability showed a high positive direct effect along with positive genetic correlation on grain yield per plant next to the major yield contributing trait number of productive tillers per plant. Hence, genotypes that have high membrane thermostability, low relative injury offer scopes for direct selection/hybridization for future elaborate investigations on high temperature tolerance in rice (Maavimani et al., 2014).

It can be drawn from some of the above mentioned roles of HSPs, plant hormones, plant growth regulators, osmoprotectants, and thermal stability that heat tolerance in rice involves different mechanisms that account for the ability of plants to tolerate adverse effects of heat stress (figure 2). Explicit understanding of these mechanisms and how they relate to one another is of great importance for successfully encountering heat stress in rice.

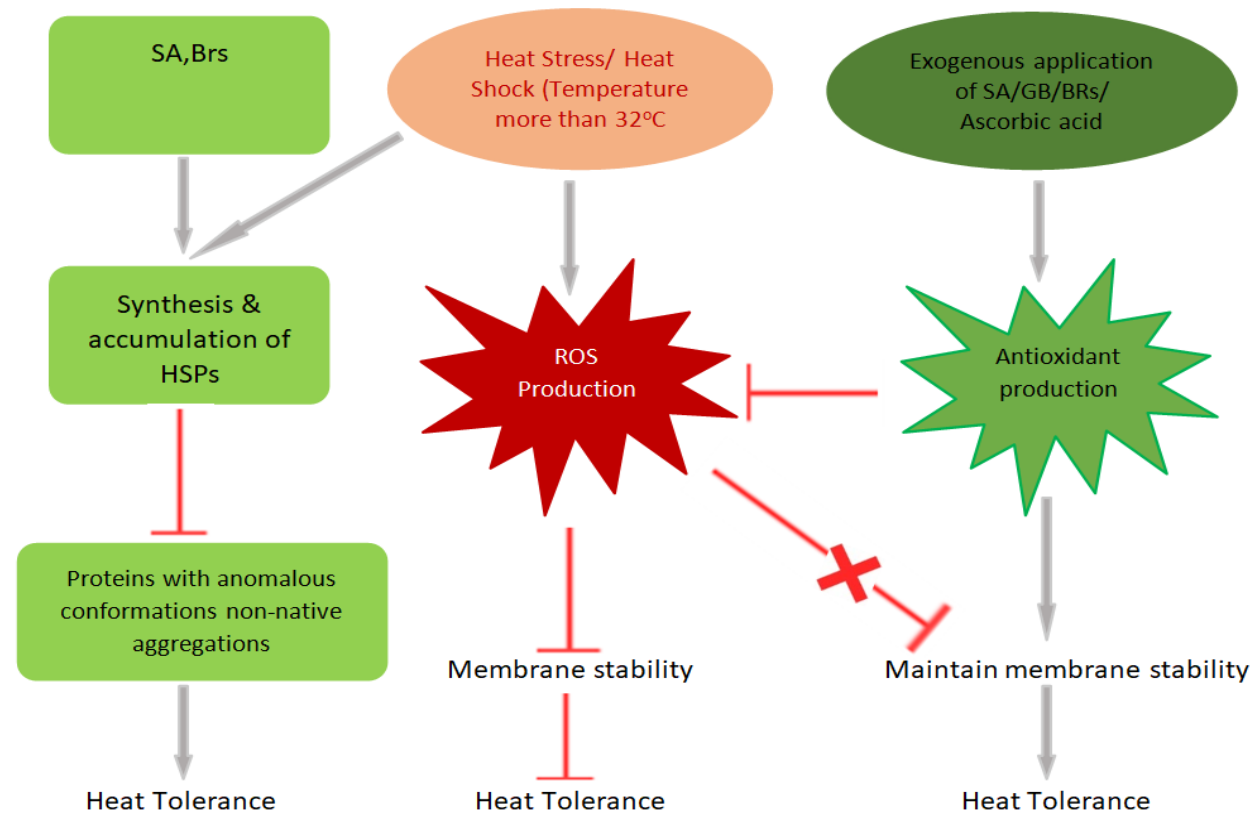

Figure 2 Some possible mechanisms to ameliorate heat stress in rice

Journal of Experimental Biology and Agricultural Sciences http://www.jebas.org 
Heat stress (temperature more than $32^{\circ} \mathrm{C}$ ) resulted in the induction and synthesis of HSPs in some rice plant species. The HSPs helps in the elimination of proteins with anomalous conformations, as well as eliminate proteins with nonnative aggregations, thereby helping the plant in coping with the heat stress effects. Synthesis of HSPs can be induced by exogenous application of Salicylic acid (SA) and Brassinosteroids (Brs). Heat stress can lead to an increase in the accumulation of reactive oxygen species (ROS) which can decrease and damage membrane stability, leading to a decline in plant growth and productivity. Exogenous application of SA, Glycine betaine (GB)/ Brassinosteroids (Brs), and Ascorbic acid help in the production of antioxidants that help in maintaining membrane stability and heat stress tolerance in rice.

\section{Conclusions}

Heat stress can damage most of the physiological processes of growth and reproduction in rice. As an increase in global temperature has become a reality, it has become more important to expedite our understanding of the mechanisms to face the global issue of food crisis. Hence, the present scenario demands a clarion call to all the scientific communities to look for different measures to understand heat tolerance mechanisms to produce plants that can produce optimal yields under harsh environmental conditions. Understanding every mechanism will help us in selecting the best traits and interventions to encounter heat stress. It is suggested that a deeper understanding of the roles of various desirable traits and roles of hormones, plant growth regulators, HSPs, and osmoprotectants, complemented with genetic modification and breeding techniques will greatly help in effective dealing of heat stress problems.

\section{Conflicts of interest}

Nil

\section{References}

Abdul-Razack M, Lee T (2009) Impact of high night time temperature on respiration, membrane stability, antioxidant capacity, and yield of rice plants. Crop Science 49: 313-322.

Ahmed J, Hasan M (2011) Evaluation of seedling proline content of wheat genotypes in relation to heat tolerance. Bangladesh Journal of Botany 40: 17-22.

Annunziata MG, Ciarmiello LF, Woodrow P, Dell'Aversana E, Carillo P ( 2019) Spatial and temporal profile of glycine betaine accumulation in plants under abiotic stresses. Frontiers in Plant Science 10 (230): 1-13.

Anwar A, Liu Y, Dong R, Bai L, Yu X, Li Y (2018) The physiological and molecular mechanism of brassinosteroid in response to stress: A review. Biological Research 51 (46): 1-15
Bahuguna RN, Jha J, Pal M, Shah D, Lawas LM, Khetarpal S, Jagadish KSV (2015) Physiological and biochemical characterization of NERICA-L-44: a novel source of heat tolerance at the vegetative and reproductive stages in rice. Physiologia Plantarum 154: 543-559.

Bheemanahalli R, Sathishraj R, Manoharan M, Sumanth HN, Muthurajan R, Ishimaru T, Krishna JSV ( 2017) Is early morning flowering an effective trait to minimize heat stress damage during flowering in rice? Field Crops Research 203: 238-242.

Blum A, Ebercon A (1981) Cell membrane stability as a measure of drought and heat tolerance in wheat. Crop Science 21: 43-47.

Chandrakala JU, Chaturvedi AK, Ramesh KV, Rai P, Khetarpal S, Pal M (2013) Acclimation response of signalling molecules for high temperature stress on photosynthetic characteristics in rice genotypes. Indian Journal of Plant Physiology 18: 142-150.

Chang PFL, Jinn TL, Huang WK, Chen Y, Chang HM, Wang CW (2007) Induction of a cDNA clone from rice encoding a class II small heat shock protein by heat stress, mechanical injury, and salicylic acid. Plant Science 172: 64-75.

Das S, Krishnan P, Nayak M, Ramakrishnan B (2014) High temperature stress effects on pollens of rice (Oryza sativa L.) genotypes. Environmental and Experimental Botany 101: 36-46.

De Ronde JA, Cress WA, Kruger GHJ, Strasser RJ, Van Staden J (2004) Photosynthetic response of transgenic soybean plants, containing an Arabidopsis P5CR gene, during heat and drought stress. Journal of Plant Physiology 161: 1211-1224.

Dhaubhadel S, Browning KS, Gallie DR, Krishna P (2002) Brassinosteroid functions to protect the translational machinery and heat-shock protein synthesis following thermal stress. The Plant Journal 29: 681-691.

Dionisio-Sese ML, Shono M, Tobita S (2000) Effects of proline and betaine on heat inactivation of ribulose-1, 5-bisphosphate carboxylase/oxygenase in crude extracts of rice seedlings. Photosynthetica 36: 557-563.

Fahad S, Ali AB , Nazir U, Anjum SA, Farooq A, Zohaib A, Sadia S, Nasim W, Adkins S, Saud S, Ihsan MZ, Alharby H, Wu C, Wang D, Huang J (2017) Crop production under drought and heat stress: plant responses and management options. Frontiers in Plant Science 8: 1147.

Fahad S, Hussain S, Saud S, Hassan S, Ihsan Z, Shah AN, Wu C, Yousaf M, Nasim W, Alharby H, Alghabari F, Huang J (2016a) Exogenously applied plant growth regulators enhance the morphophysiological growth and yield of rice under high temperature. Frontiers in Plant Science 7: 1250. 
Fahad S, Hussain S, Saud S, Khan F, Hassan S, Amanullah, Nasim W, Arif M, Wang F, Huang J (2016b) Exogenously applied plant growth regulators affect heat-stressed rice pollens. Journal of Agronomy and Crop Science 202: 139-150.

Farooq M, Wahid A, Lee DJ (2009) Exogenously applied polyamines increase drought tolerance of rice by improving leaf water status, photosynthesis and membrane properties. Acta Physiologiae Plantarum 31(5): 937-945.

Forkar M, Nguyen HT, Blum A (1998) Heat tolerance in spring wheat. I. Estimating cellular thermostability and its heritability. Euphytica 104: 1-8.

Govindaraj M, Pattanashetti SK, Patne N, Kanatti AA (2018) Breeding cultivars for heat stress tolerance in staple food crops. In: Çiftçi YÖ (Ed.) Next generation plant breeding. InTechOpen.

Hasanuzzaman M, Hossain MA, da Silva JAT, Fujita M (2012) Plant responses and tolerance to abiotic oxidative stress: Antioxidant defenses is a key factor. In: Crop Stress and Its Management: Perspectives and Strategies. Springer; Berlin, Germany, 261-316.

Hasanuzzaman M, Nahar K, Fujita M (2013) Extreme temperatures, oxidative stress and antioxidant defense in plants. In: Abiotic Stress: Plant Responses and Applications in Agriculture. InTech; Rijeka, Croatia, Pp. 169-205.

Hayat Q, Hayat S, Irfan M, Ahmad A (2010) Effect of exogenous salicylic acid under changing environment: A review. Environmental and Experimental Botany 68: 14-25.

Huang B, Xu C (2008) Identification and characterization of proteins associated with plant tolerance to heat stress. Journal of Integrative Plant Biology 50: 1230-1237.

Jagadish SVK, Craufurd PQ, Wheeler TR (2007) High temperature stress and spikelet fertility in rice (Oryza sativa L.). Journal of Experimental Botany 58: 1627-1635.

Jagadish SVK, Muthurajan R, Oane R, Wheeler T, Heuer S, Bennett J, Craufurd PQ (2010) Physiological and proteomic approaches to address heat tolerance during anthesis in rice. Journal of Experimental Botany 61: 143-156.

Jain R, Solomon S, Shrivastava AK, Lal P (2001) Nutrient application improves stubble bud sprouting under low temperature conditions in sugarcane. Sugar Tech 11(1):83-85.
Julia C, Dingkuhn M (2012) Variation in time of day of anthesis in rice in different climatic environments. European Journal of Agronomy 43: 166-174.

Julia C, Dingkuhn M (2013) Predicting temperature induced sterility of rice spikelets requires simulation of crop-generated microclimate. European Journal of Agronomy 49: 50-60.

Katiyar-Agarwal S, Agarwal M, Grover A (2003) Heat-tolerant basmati rice engineered by over-expression of hsp101. Plant Molecular Biology 51: 677-686.

Keller M SPOT-ITN Consortium, Simm S (2018) The coupling of transcriptome and proteome adaptation during development and heat stress response of tomato pollen. BMC Genomics 19: 447.

Kobayasi K, Atsuta Y (2010) Sterility and poor pollination due to early flower opening induced by methyl jasmonate. Plant Production Science 13: 29-36.

Koh S, Lee S Ch, Kim MK, Koh JH, Lee S, An G, Choe S, Kim SR (2007) T-DNA tagged knockout mutation of rice OsGSK1, an orthologue of Arabidopsis BIN2, with enhanced tolerance to various abiotic stress. Plant Molecular Biology 65: 453-466.

Kotak S, Larkindale J, Lee U, von Koskull-Döring P, Vierling E, Scharf KD (2007) Complexity of the heat stress response in plants. Current Opinion in Plant Biology 10: 310-316.

Lei G, Zhang HY, Wang ZH, Wei LX, Fu P, Song JB, Fu DH, Huang YJ, Liao JL (2018) High night time temperature induces antioxidant molecule perturbations in heat-sensitive and heattolerant coisogenic rice (Oryza sativa) strains. Journal of Agricultural and Food Chemistry 66: 12131-12140.

Levitt J (1980) Responses of plants to environmental stresses. Academic Press, New York.

Maavimani M, Jebaraj S, Raveendran M, Vanniarajan C, Balakrishnan K, Muthamilan M (2014) Cellular membrane thermostability is related to rice (Oryza sativa $\mathrm{L}$ ) yield under heat stress. International Journal of Tropical Agriculture 32: 201-208.

Maestri E, Klueva N, Perrota C, Gulli M, Nguyen HT, Marmiroli N (2002) Molecular genetics of heat tolerance and heat shock proteins in cereals. Plant Molecular Biology 48: 667-681.

Mäkelä P, Karkkainen J, Somersalo S (2000) Effect of glycine betaine on chloroplast ultrastructure, chlorophyll and protein content, and RUBPCO activities in tomato grown under drought or salinity. Biologia Plantarum 3: 471-475. 
Mohammed AR, Tarpley L (2011) Effects of night temperature, spikelet position and salicylic acid on yield and yield-related parameters of rice (Oryza sativa L.). Journal of Agronomy and Crop Science 197: 40-49.

Mostofa MG, Yoshida N, Fujita M (2014) Spermidine pretreatment enhances heat tolerance in rice seedlings through modulating antioxidative and glyoxalase systems. Plant Growth Regulation 73(1): 31-44.

Naeem S, Atique-ur-Rehman, Farooq O, Wasaya A, Saliq S , Mubeen K (2019) Improved auxin level at panicle initiation stage enhance the heat stress tolerance in rice plants. In: () Proceedings of the 2019 Agronomy Australia Conference, Australia 1-4.

Nounjan N, Nghia PT, Theerakulpisut P (2012) Exogenous proline and trehalose promote recovery of rice seedlings from salt-stress and diferentially modulate antioxidant enzymes and expression of related genes. Journal of Plant Physiology 169(6):596-604.

Oh-e I, Saitoh K, Kuroda T (2007) Effects of high temperature on growth, yield and dry-matter production of rice grown in the paddy field. Plant Production Science 10: 412-422.

Prasad PVV, Bheemanahalli R, Jagadish SVK (2017) Field crops and the fear of heat stress - opportunities, challenges and future directions. Field Crops Research 200: 114-121.

Quan R, Shang M, Zhang H, Zhao Y, Zhang J (2004) Engineering of enhanced glycine betaine synthesis improves drought tolerance in maize. Plant Biotechnology Journal 2: 477-486.

Rasheed R, Wahid A, Farooq M, Hussain I, Basra SMA (2011) Role of proline and glycine betaine pretreatments in improving heat tolerance of sprouting sugarcane (Saccharum sp.) buds. Plant Growth Regulation 65(1):35-45.

Reynolds MP, Balota M, Delgado MIB, Amani I Fischer RA (1994) Physiological and morphological traits associated with spring wheat yield under hot, irrigated conditions. Australian Journal of Plant Physiology 21: 717-730.

Sadalla MM, Shanahan JF, Quick JS (1990) Heat tolerance in winter wheat. I. Hardening and genetic effects on membrane thermostability. Crop Science 30: 1243-1247.

Sailaja B, Subrahmanyam D, Neelamraju S, Vishnukiran T, Rao YV, Vijayalakshmi P, Voleti SR, Bhadana VP, Mangrauthia SK (2015) Integrated physiological, biochemical, and molecular analysis identifies important traits and mechanisms associated with differential response of rice genotypes to elevated temperature. Frontiers in Plant Science 6: 1044.
Sakamoto A, Murata N (2002) The role of glycine betaine in the protection of plants from stress: clues from transgenic plants. Plant, Cell and Environment 25(2):163-171.

Satake T, Yoshida S (1978) High temperature induced sterility in indica rices at flowering. Japanese Journal of Crop Science 47: 6-17.

Sheehy JE, Elmido A, Centeno G, Pablico P (2005) Searching for new plants for climate change. Journal of Agricultural Meteorology 60: 463-468.

Sonjaroon W, Thussagunpanit J, Jutamanee K, Khamsuk O, Suksamrarn A (2017) Exposure brassinosteroid and brassinosteroid mimics continually improve photosynthesis in rice subject to heat stress. Agrotechnology 6: 4.

Sullivan CY (1972) Mechanisms of heat and drought resistance in grain sorghum and method of measurements. In: Rao NGP, House LR (Eds.) Sorghum in the seventies Oxford and IBH Publication, New Delhi, 247-264.

Szabados L, Savoure' A (2010) Proline: A multifunctional amino acid. Trends in Plant Science 15: 89-97.

Tang RS, Zheng JC, Jin ZQ, Zhang DD, Huang YH, Chen LG (2008) Possible correlation between high temperature induced floret sterility and endogenous levels of IAA, GAs and ABA in rice (Oryza sativa L.) Plant Growth Regulation 54:37-43.

Tang S, Zhang H, Li CL, Liu X, Chen L, Chen W, Ding Y (2018) Exogenous spermidine enhances the photosynthetic and antioxidant capacity of rice under heat stress during early grainfilling period. Functional Plant Biology 45: 911-921.

Tian J, Guo S, Liu X, Zhang R, Cheng Y (2009) Effects of exogenous spermidine pretreatment on antioxidant system in cucumber seedling leaves under high temperature stress. Acta Botanica Boreali Occidentalia Sinica 11: 20.

Wahid A, Gelani S, Ashraf M, Foolad M (2007) Heat tolerance in plants: an overview. Environmental and Experimental Botany 61: 199-223.

Weerakoon WMW, Maruyama A, Ohba K (2008) Impact of humidity on temperature-induced grain sterility in rice (Oryza sativa L.). Journal of Agronomy and Crop Science 194: 135-140.

Xiong D, Yu T, Ling X, Fahad S, Peng S, Li Y, Huang J (2014) Sufficient leaf transpiration and nonstructural carbohydrates are beneficial for high-temperature tolerance in three rice (Oryza sativa) cultivars and two nitrogen treatments. Functional Plant Biology 42: 347-356. 
Yamanouchi U, Yano M, Lin H, Ashikari M, Yamada K (2002) A rice spotted leaf gene, Spl7, encodes a heat stress transcription factor protein. Proceedings of the National Academy of Sciences 99: 7530-7535.

Yoshida S (1981). Fundamentals of rice crop science. Los Baños, The Philippines: IRRI.

Zeng XC, Zhou, Zhang W, Murofushi N, Kitahara T, Kamuro (1999) Opening of rice floret in rapid response to methyl jasmonate. Journal of Plant Growth Regulation 18: 153-158.

Zhang CX, Feng BH, Chen TT, Zhang XF,Tao LX, Fu GF (2017) Sugars, antioxidant enzymes and IAA mediate salicylic acid to prevent rice spikelet degeneration caused by heat stress. Journal of Plant Growth Regulation 83: 313-323.

Zhang QL, Wei YX, Peng CL (2018) Effects of endogenous ascorbic acid on resistance to high-temperature stress in excised rice leaves. Photosynthetica 56: 1453-1458. 